\title{
Diagnóstico sorológico de erliquiose canina com antígeno brasileiro de Ehrlichia canis
}

\author{
Serological diagnosis of canine monocytic ehrlichiosis with Brazilian antigen of Ehrlichia canis
}

\author{
Daniel Moura Aguiar ${ }^{\mathrm{I}, \mathrm{IV}}$ Taís Berelli Saito ${ }^{\mathrm{II}}$ Mitika Kuribayashi Hagiwara ${ }^{\mathrm{II}}$ \\ Rosângela Zacarias Machado ${ }^{\mathrm{III}}$ Marcelo Bahia Labruna ${ }^{\mathrm{IV}}$
}

\section{RESUMO}

$O$ presente trabalho relata o isolamento de Ehrlichia canis em cultivo de células DH82 e posterior padronização da Reação de Imunofluorescência Indireta (RIFI). Leucócitos de uma cadela experimentalmente infectada com o isolado Jaboticabal de E. canis foram inoculados em cultivo de células DH82. A inoculação foi monitorada após a segunda semana, a cada 5-6 dias, através de exames citológicos e pela amplificação de um fragmento do gene dsb de Ehrlichia pela Reação em Cadeia pela Polimerase (PCR) para confirmação da infecção. A cultura apresentou-se positiva aos 27 dias pós-inoculação pela PCR e aos 28 dias pela citologia. No $33^{\circ}$ dia pós-inoculação, observou-se $20 \%$ de células infectadas e, aos 53 dias, 60\% de infecção. Atualmente, o isolado encontra-se estabelecido em células DH82, com várias passagens atingindo 90-100\% de células infectadas entre 710 dias após a inoculação. Após o seqüenciamento do produto de PCR, o isolado apresentou-se $100 \%$ similar à seqüencia correspondente de E. canis depositada no GenBank. As células infectadas foram utilizadas como antígeno para a padronização da RIFI para detecção da infecção em cães.

Palavras-chave: Ehrlichia canis, isolamento, DH82, imunofluorescência, sorologia.

\section{ABSTRACT}

The present study describes a successful isolation of Ehrlichia canis and its establishment in DH82 cells, followed by the development of an Indirect Fluorescent Antibodies Test (IFAT). Leukocytes collected from an experimentally infected dog with the Jaboticabal strain of $\boldsymbol{E}$. canis were used to inoculate a DH82 cell monolayer. Two weeks later, the inoculated culture

\begin{abstract}
was checked for infectivity, every 5-6 days by both cytological staining and PCR, targeting a fragment of the dsb gene. The cell culture showed to be infected by Ehrlichia on day 27 by PCR and on day 28 by cytological staining. By the day 33, the infection rate reached $20 \%$ and on day 53, $60 \%$. Currently, the isolate is established in DH82 cells, with several passages reaching $90-100 \%$ of infected cells, within 7 to 10 days post inoculation. After sequencing, the amplicon was identical to other $\boldsymbol{E}$. canis corresponding sequences available in the GenBank. DH82 infected cells were used to standardize an IFAT for the diagnosis of canine ehrlichiosis.
\end{abstract}

Key words: Ehrlichia canis, isolation, DH82, immunofluorescence, serology.

\section{INTRODUÇÃO}

O gênero Ehrlichia atualmente compreende cinco espécies válidas: Ehrlichia canis, E. chaffeensis, E. ewingii, E. muris e E. ruminantium (DUMLER et al., 2001). São bactérias gram-negativas, parasitas intracelulares obrigatórios de células hematopoiéticas maduras ou imaturas, especialmente do sistema fagocitário mononuclear, tais como monócitos e macrófagos e, para algumas espécies, em células mielóides, tais como neutrófilos (DUMLER et al., 2001).

No Brasil, a única espécie descrita até o momento é E. canis, responsável pela erliquiose

\footnotetext{
IAgência Paulista de Tecnologia dos Agronegócios, Pólo Regional da Alta Sorocabana. Rod. Raposo Tavares, Km 563, CP 298, 19015-970, Presidente Prudente, SP, Brasil. E-mail: danmoura@aptaregional.sp.gov.br. Autor para correspondência.

IDDepartamento de Clínica Veterinária, Faculdade de Medicina Veterinária e Zootecnia (FMVZ), Universidade de São Paulo (USP), São Paulo, SP, Brasil.

IIIDepartamento de Patologia Veterinária, Faculdade de Ciências Agrárias e Veterinárias (FCAV), Universidade Estadual Paulista (UNESP), Jaboticabal, SP, Brasil.

Iv Departamento de Medicina Veterinária Preventiva e Saúde Animal, FMVZ, USP. São Paulo, SP, Brasil.
} 
monocítica canina, doença considerada endêmica principalmente nas áreas urbanas, onde abundam populações do carrapato vetor, Rhipicephalus sanguineus (LABRUNA \& PEREIRA, 2001). Em Belo Horizonte, COSTA et al. (1973) relataram pela primeira vez a doença no Brasil. Posteriormente, foi relatada acometendo aproximadamente $20 \%$ dos cães atendidos em hospitais e clínicas veterinárias de Estados das regiões Nordeste, Sudeste, Sul e Centro-Oeste (LABARTHE et al., 2003; MOREIRA et al., 2003).

A $\boldsymbol{E}$. canis pode ser cultivada in vitro em células DH82 (dog histiocytosis), linhagem originária de monócitos caninos, que foi adaptada em cultivo celular a partir de células obtidas de um caso de histiocitoma (WELLMAN et al., 1988). Até o momento, são vários os isolados de $\boldsymbol{E}$. canis cultivados in vitro e geneticamente caracterizados na América do Norte e no Velho Mundo. No caso da América Latina, o isolamento in vitro de $\boldsymbol{E}$. canis de cães tem sido reportado apenas no Estado do Rio de Janeiro, no Brasil (TORRES et al., 2002) e na Venezuela (UNVER et al., 2001). Neste último país, há um relato recente de pelo menos seis casos clínicos de erliquiose humana causada por $\boldsymbol{E}$. canis, indicando que este agente pode causar infecções zoonóticas (PEREZ et al., 2005).

O presente trabalho relata o cultivo in vitro de um isolado de $\boldsymbol{E}$. canis em células DH82 e a padronização da Reação de Imunofluorescência Indireta (RIFI) para diagnóstico sorológico da erliquiose canina no Brasil.

\section{MATERIAL E MÉTODOS}

Origem do isolado e obtenção do inóculo de $\boldsymbol{E}$. canis. Uma cepa de $\boldsymbol{E}$. canis foi isolada de um cão fêmea da raça Weimaraner, em fase aguda da doença, por um dos autores (R. Z. MACHADO, dados nãopublicados), em 1993, na cidade de Jaboticabal-SP, sendo mantida até o presente por passagens em cães através da inoculação de sangue infectado e em amostras de sangue infectado congelado. Esta cepa foi designada como cepa Jaboticabal. Para o presente estudo, uma cadela saudável, sem raça definida, de aproximadamente três anos, vermifugada, vacinada contra as principais doenças caninas e com exame de PCR (gene $d s b$, protocolo descrito abaixo) negativo para erliquiose, foi inoculada com cinco mililitros $(5 \mathrm{ml})$ de sangue total sem anticoagulante, infectado pela cepa Jaboticabal de $\boldsymbol{E}$. canis. Após a inoculação, a cadela foi acompanhada diariamente, até o aparecimento dos sinais clínicos da erliquiose (anorexia, apatia, linfoadenopatia e febre), quando foram realizados exame hematológico e PCR. Paralelamente, foram realizados esfregaços de sangue periférico corado pelo Panótico Rápido $\left(\right.$ Laborclin $^{\circledR}$ ) para visualização de estruturas compatíveis com mórulas de $\boldsymbol{E}$. canis.

Reação em cadeia pela polimerase (PCR) e sequenciamento.

No momento do aparecimento de quadros febris e do primeiro encontro de mórulas no esfregaço sangüíneo da cadela inoculada, o sangue foi analisado pela PCR visando à amplificação de um fragmento do gene $d s b$ de Ehrlichia, utilizando-se os primers Dsb330 (5'-GAT GAT GTC TGAAGA TAT GAAACAAAT3') e Dsb-729 (CTG CTC GTC TAT TTT ACT TCT TAA AGT-3'), conforme protocolo descrito por KUYLERDOYLE et al. (2005). Uma vez detectado o fragmento amplificado no tamanho esperado de $409 \mathrm{pb}$, este foi submetido ao sequenciamento em um sequenciador automático de DNA modelo ABI Prism 310 Genetic Analyser (Applied Biosystens/Perkin Elmer), segundo seu manual de instruções. As seqüências obtidas foram comparadas com outras seqüências de Ehrlichia spp disponíveis no GenBank.

Inoculação em células DH82.

A amostra de sangue, quando positiva pela citologia e para PCR, foi processada para o isolamento de leucócitos, utilizando o protocolo descrito por PADDOCK et al. (1997), baseado no uso de Histopaque 1083 (Sigma Diagnostics, St. Luis, Mo). Os leucócitos foram então inoculados em monocamadas de células DH82 (ATCC $n^{\circ}$ : CRL-10389; WELLMAN et al., 1988), repicadas três dias antes e mantidas a $37^{\circ} \mathrm{C}$ e $5 \%$ de $\mathrm{CO}_{2}$. Para o crescimento e a manutenção celulares, foi utilizado o meio Dulbecco's Modified Eagle's (Sigma Aldrich $^{\circledR}$ ) acrescido de 5\% de soro de bezerro (Bovine Calf Serum - BCS; Hyclone ${ }^{\circledR}$ ), renovado parcialmente a cada 3-4 dias.

A monocamada inoculada foi acompanhada após a segunda semana, a cada 5-6 dias, por exames citológicos, corados com o Kit Panótico rápido $\left(\right.$ Laborclin $^{\circledR}$ ) e pela PCR do gene $d s b$ para confirmação da infecção. Uma vez que a monocamada desta primeira passagem apresentasse um mínimo de 50\% de infecção, alíquotas de seu sobrenadante eram inoculadas em novas monocamadas não-infectadas, a fim de estabelecer passagens do isolado. Este procedimento foi realizado em passagens subseqüentes, até que a monocamada apresentasse 90 a 100\% de infecção dentro de poucos dias após a inoculação, implicando o estabelecimento do isolado em cultivo celular.

Alíquotas de células infectadas das primeira e quarta passagens do isolado foram submetidas à PCR conforme descrito acima. O produto amplificado foi 
seqüenciado para confirmar a identidade da espécie de Ehrlichia isolada e estabelecida em cultivo celular.

Preparo do antígeno e padronização da reação de imunofluorescência indireta (RIFI)

As monocamadas, quando apresentaram 80-90\% de infecção, foram desprendidas da garrafa com auxilio de raspadores apropriados (Corning ${ }^{\circledR}$ ) e a suspensão de células foi centrifugada a $4.000 \mathrm{~g}$ por 5 minutos. Desprezado o sobrenadante, as células foram ressuspendidas em Solução Tampão Fosfatada (PBS; $\mathrm{pH} 7,2 ; 0,0084 \mathrm{MNa}_{2} \mathrm{HPO}_{4}, 0,0018 \mathrm{MNaH}_{2} \mathrm{PO}_{4}$ e $0,147 \mathrm{M}$ $\mathrm{NaCl}$ ) para obter uma concentração de 10.000 células por ml. Dez $\mu 1$ da solução foram adicionados em cada orifício de lâminas apropriadas para a imunofluorescência, que foram secadas em temperatura ambiente por duas horas. As lâminas foram fixadas em acetona por 10 minutos e depois estocadas a $-20^{\circ} \mathrm{C}$ até o momento do uso.

O antígeno, depois de preparado, foi testado com um banco de 20 soros de cães previamente analisados por dois Kits comerciais de diagnóstico sorológico para $\boldsymbol{E}$. canis: Ensaio Imunoenzimático ELISA (SNAP 3Dx ${ }^{\circledR}$ Test) e RIFI com antígeno proveniente do isolado Oklahoma de $\boldsymbol{E}$. canis (VRMD Pullman ${ }^{\circledR}$; considerado como o teste padrão para pesquisa de anticorpos anti-E. canis), conforme instruções técnicas dos fabricantes. A RIFI com antígeno Jaboticabal foi realizada segundo RISTIC et al. (1972), com ponto de corte estipulado na diluição de 1:40, conforme adotado por McBRIDE et al. (2001), sendo utilizado conjugado IgG de coelho anti-IgG canino (produzido pelo Centro de Controle de Zoonoses - CCZ - município de São Paulo, SP), marcado com isotiocianato de fluoresceína na diluição de 1:640. As amostras consideradas positivas foram sucessivamente diluídas, na razão dois, para obtenção do título final. A leitura das lâminas foi realizada em microscópio de epifluorescência OLIMPUS ${ }^{\circledR}$. A partir destes resultados, foi possível estimar os valores de sensibilidade e especificidade para a RIFI produzida com o isolado Jaboticabal e para o teste de ELISA.

Avaliação de soros provenientes de cães atendidos no HOVET e de cães inoculados com o isolado Jaboticabal

Após a padronização da RIFI (isolado Jaboticabal), foram avaliados aleatoriamente soros sangüíneos de 23 cães atendidos no Hospital Veterinário (HOVET) da Faculdade de Medicina Veterinária e Zootecnia (FMVZ) da Universidade de São Paulo (USP) e de sete cães inoculados experimentalmente com o isolado Jaboticabal de $\boldsymbol{E}$. canis. No histórico dos cães do HOVET, constava a presença de sintomatologia clínica variável (alguns compatíveis com erliquiose canina) e/ou o relato de encontro de carrapatos. O soro controle positivo foi oriundo de um cão inoculado com a amostra Jaboticabal de $\boldsymbol{E}$. canis (HASEGAWA et al., 2005), com título final de 5.120. A reação foi processada conforme descrito no tópico anterior.

\section{RESULTADOS}

Isolamento de $\boldsymbol{E}$. canis em células DH82

Após a inoculação da cadela com o isolado Jaboticabal de E. canis, as alterações clínicas (apatia, febre e linfoadenopatia) foram observadas a partir de 14 dias. O exame hematológico demonstrou: hemácias: $6,1 \times 10^{6} \mathrm{~mm}^{-3}$; hematócrito: $40 \%$; contagem total de leucócitos: $3.000 \mathrm{~mm}^{-3}$; plaquetas $47.000 \mathrm{~mm}^{-3}$. No 14 o dia pós-inoculação, verificou-se o aparecimento de mórulas em monócitos sanguíneos, quando houve também a confirmação pela PCR. No $15^{\circ}$ dia pósinoculação, durante o pico febril de $41^{\circ} \mathrm{C}$, foi colhido $10 \mathrm{ml}$ de sangue heparinizado, que foi processado para ser inoculado numa monocamada de células DH82 nãoinfectadas. No 27ำ dia pós-inoculação, obteve-se o primeiro resultado positivo na PCR (Figura 1), confirmando o isolamento com a visualização de mórulas no exame citológico aos 28 dias (Figura 2). No $33^{\circ}$ dia pós-inoculação, $20 \%$ das células estavam infectadas e, aos 53 dias, $60 \%$ delas. Neste momento, o sobrenadante da cultura infectada $(5 \mathrm{ml})$ foi inoculado em nova monocamada de células DH82, a fim de dar prosseguimento ao cultivo. A partir desta primeira passagem, amostras de células infectadas foram criopreservadas a $-80^{\circ} \mathrm{C}$, em soro de bezerro com $10 \%$ de Dimetilsulfóxido (DMSO) a fim de se estocar o isolado obtido. Atualmente, o isolado encontra-se estabelecido em células DH82, com várias passagens atingindo $90-100 \%$ de células infectadas dentro de 710 dias após a inoculação.

Sequenciamento do gene dsb do isolado Jaboticabal de E. canis

Os produtos amplificados do gene $d s b$ do sangue do cão inoculado e do cultivo celular (primeira e quarta passagens) foram seqüenciados. Após exclusão das porções correspondentes aos primers, foi obtido um fragmento de 350 nucleotídeos de cada produto amplificado. As seqüências mostraram-se idênticas entre si e, quando comparadas com as seqüências disponíveis no GenBank, apresentaram $100 \%$ de similaridade com a seqüência correspondente ao isolado Norte-Americano Jake de E. canis 


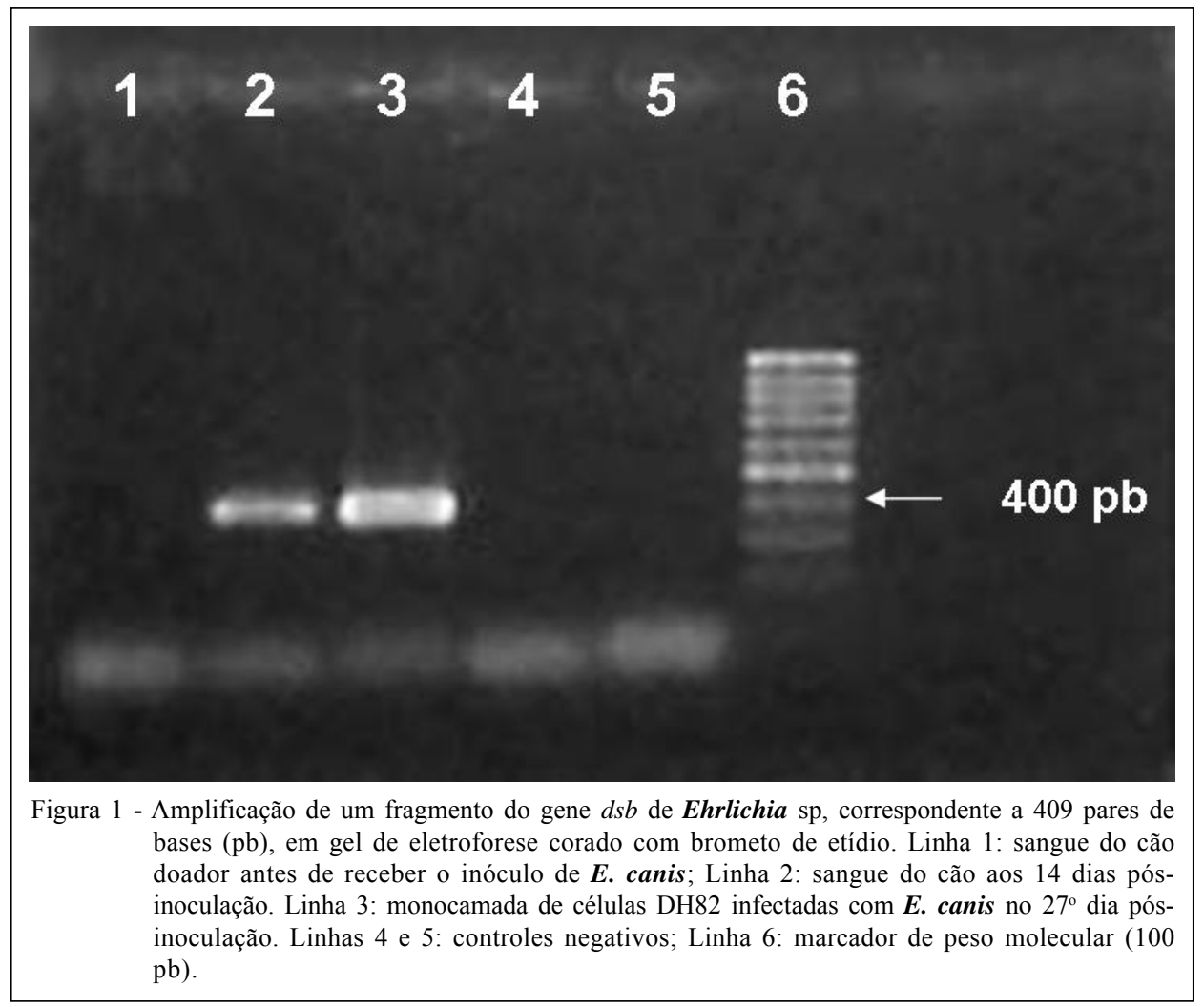

(AF403710). A seqüência parcial do gene $d s b$ do isolado Jaboticabal gerado neste estudo foi depositada no GenBank, sob número de acesso DQ460716.

\section{Padronização da RIFI}

A tabela 1 sumariza os resultados obtidos na análise sorológica dos soros positivos e negativos, frente aos antígenos comerciais (SNAP 3Dx ${ }^{\circledR}$ Test e VRMD Pullman ${ }^{\circledR}$ ) e ao isolado Jaboticabal. Por questões logísticas, os soros positivos testados pelo antígeno
VRMD não foram titulados até o fim. Considerando-se o ponto de corte de 40 para os protocolos de RIFI, 10 amostras de soros foram consideradas negativas e oito amostras foram consideradas positivas para todos os três testes sorológicos realizados. Outras duas amostras foram negativas apenas pelo ELISA. Considerando-se a RIFI com antígeno VRMD como teste padrão, o isolado Jaboticabal apresentou sensibilidade e especificidade de $100 \%$, enquanto que o teste de ELISA comercial (SNAP 3Dx ${ }^{\circledR}$ ) demonstrou

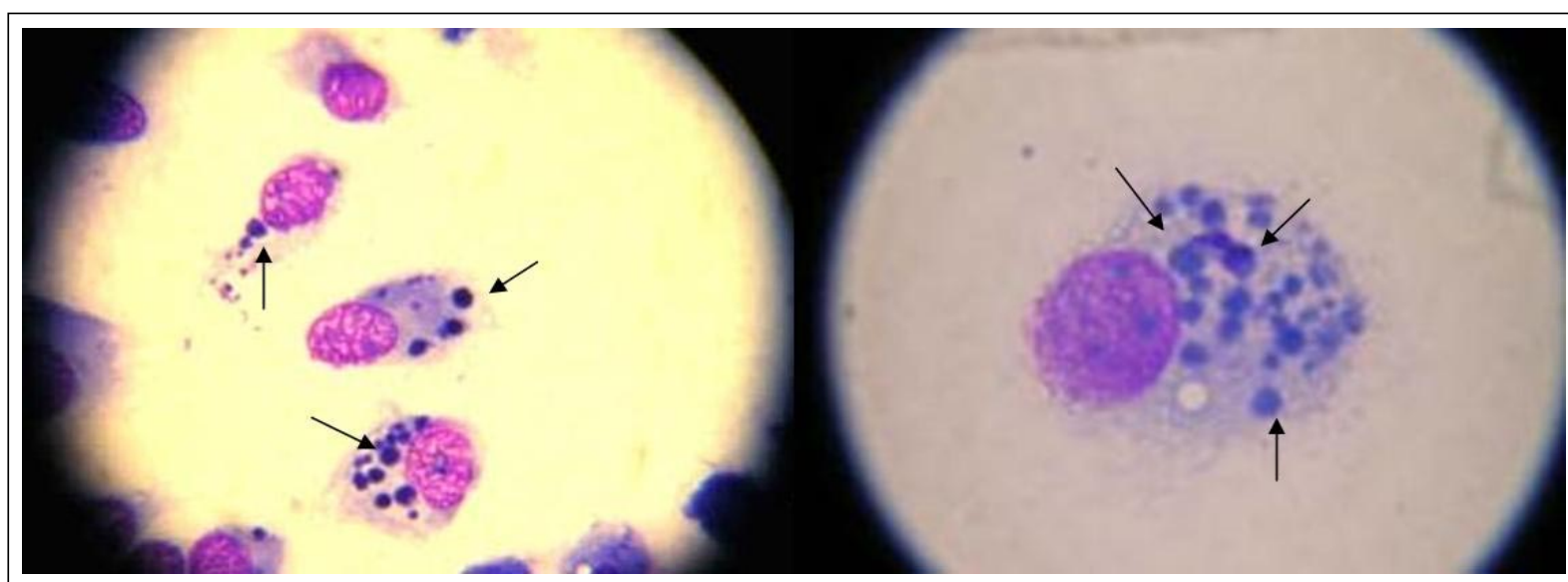

Figura 2 - Fotomicrografias de células DH82 provenientes de monocamada inoculada com o isolado de Jaboticabal, SP, apresentando mórulas de Ehrlichia canis (setas) aos 28 dias pós-inoculação. Panótico rápido (Laborclin ${ }^{\circledR}$ ); 100X. 
Tabela 1 - Pesquisa de anticorpos reagentes a Ehrlichia canis em 20 soros de cães pelo ensaio imunoenzimático ELISA e pela reação de imunofluorescência indireta (RIFI) com antígeno comercial (isolado Oklahoma) e antígeno brasileiro (isolado Jaboticabal).

\begin{tabular}{lccc}
\hline Soros & ELISA $^{1}$ & Comercial/Oklahoma $^{2}$ & Jaboticabal $^{3}$ \\
\hline 1 & Positivo & $\geq 5.120$ & 20.480 \\
2 & Positivo & $\geq 640$ & 20.480 \\
3 & Negativo & $\geq 640$ & 10.240 \\
4 & Positivo & $\geq 640$ & 40.960 \\
5 & Positivo & $\geq 160$ & 2.560 \\
6 & Positivo & $\geq 640$ & 40.960 \\
7 & Positivo & $\geq 1.280$ & 10.240 \\
8 & Positivo & $\geq 640$ & 2.560 \\
9 & Positivo & $\geq 640$ & 5.120 \\
10 & Negativo & $\geq 640$ & 2.560 \\
$11-20$ & Negativo & $<40$ & $<40$ \\
\hline
\end{tabular}

${ }^{1}$ SNAP 3Dx ${ }^{\circledR}$ Test

${ }^{2}$ VRMD Pullman ${ }^{\circledR}$; ponto de corte: 40

${ }^{3}$ Ponto de corte: 40 .

sensibilidade de $80 \%$ e especificidade de $100 \%$. A figura 3 ilustra uma reação positiva pela RIFI em microscópio de epifluorescência.

Os soros oriundos dos sete cães inoculados

com E. canis (isolado Jaboticabal) foram sororreagentes na RIFI (antígeno Jaboticabal), com títulos variando entre 1.280 e 81.920. Dos 23 cães atendidos no HOVET, 17 (68\%) apresentaram títulos de anticorpos anti-E. canis entre 40 e 20.480.

\section{DISCUSSÃO}

O presente trabalho relata o cultivo in vitro de $\boldsymbol{E}$. canis em células DH82, proveniente de cão experimentalmente infectado com a amostra Jaboticabal e a padronização da técnica da RIFI a partir das células infectadas. O cultivo in vitro de $\boldsymbol{E}$. canis vem sendo realizado em diversas partes do mundo (KEYSARY et al., 1996; UNVER et al., 2001), em células de linhagem originária de histiocitoma canino - DH82. Outras linhagens celulares têm se mostrado útil para o isolamento in vitro de $\boldsymbol{E}$. canis, como macrófago peritoneal canino (STEPHENSON \& OSTERMAN, 1977), monócito primário canino (HEMELT et al., 1980), célula endotelial humana (DAWSON et al., 1993) e células macrofágicas de camundongos BALB/C (KEYSARY et al., 2001). Antes do presente trabalho, o isolamento e o cultivo in vitro de $\boldsymbol{E}$. canis havia sido relatado no Brasil apenas uma vez, utilizando-se células DH82 (TORRES et al., 2002).
No presente trabalho, foi realizado o seqüenciamento de um fragmento do gene $d s b$ do isolado Jaboticabal de E. canis. Quando comparado com as seqüências disponíveis no GenBank, este isolado apresentou-se idêntico a um isolado norteamericano de $\boldsymbol{E}$. canis. O isolado Jaboticabal teve recentemente seu fragmento de $398 \mathrm{pb}$ do gene $16 \mathrm{~S}$ rRNA seqüenciado, demonstrando também identidade com a seqüência correspondente de $16 \mathrm{~S}$ rRNA de $\boldsymbol{E}$. canis depositada no GenBank (MACHADO, 2004). Estes dados reforçam a possibilidade de os isolados do continente americano apresentarem pouco polimorfismo.

No presente estudo, padronizou-se a RIFI a partir de células DH82 com alto índice de infecção (=80\%). A utilização do isolado Jaboticabal em soros conhecidos, previamente testados com outros antígenos comerciais (SNAP 3Dx ${ }^{\circledR}$ Test e VRMD Pullman $^{\circledR}$ ), possibilitou sua comparação, conforme adotado por DAWSON et al. (1991). No presente estudo, os resultados da RIFI com a amostra Jaboticabal de $\boldsymbol{E}$. canis apresentaram-se idênticos ao isolado Oklahoma, que é mundialmente comercializado como o teste padrão para o diagnóstico sorológico. Por outro lado, a técnica de ELISA apresentou menor sensibilidade, quando comparada à RIFI.

Os resultados encontrados no ensaio sorológico das 30 amostras ( 23 de cães do HOVET e 7 cães previamente inoculados com amostra Jaboticabal) permitem inferir sobre a utilidade deste método diagnóstico, o qual pode indicar apenas infecção prévia com o agente. No presente trabalho, oito (33\%) cães apresentaram títulos superiores a 10.240, sendo que cinco deles eram cães inoculados experimentalmente. No momento da realização do teste sorológico, esses cães não apresentavam sintomatologia clínica.

Dos 23 cães atendidos no HOVET com sinais variáveis (muitos dos quais, com sintomas sugestivos de erliquiose canina - dados não mostrados), 17 (68\%) apresentaram títulos $\geq$ a 40 de anticorpos anti-E. canis. Com esse resultado, reforçamos a possibilidade do uso do teste sorológico como auxiliar no diagnóstico da erliquiose canina, desde que aliados ao histórico e ao exame clínico do cão.

Destaca-se, nesta pesquisa, a manutenção contínua do isolado Jaboticabal de $\boldsymbol{E}$. canis em células DH82 e, conseqüentemente, sua utilização na produção de antígenos para o diagnóstico complementar da erliquiose canina brasileira. Esta amostra de E. canis, adaptada a cultivo celular, encontra-se depositada e disponível na Coleção de riquétsias e erlíquias do Laboratório de Doenças Parasitárias da FMVZ/USP. 


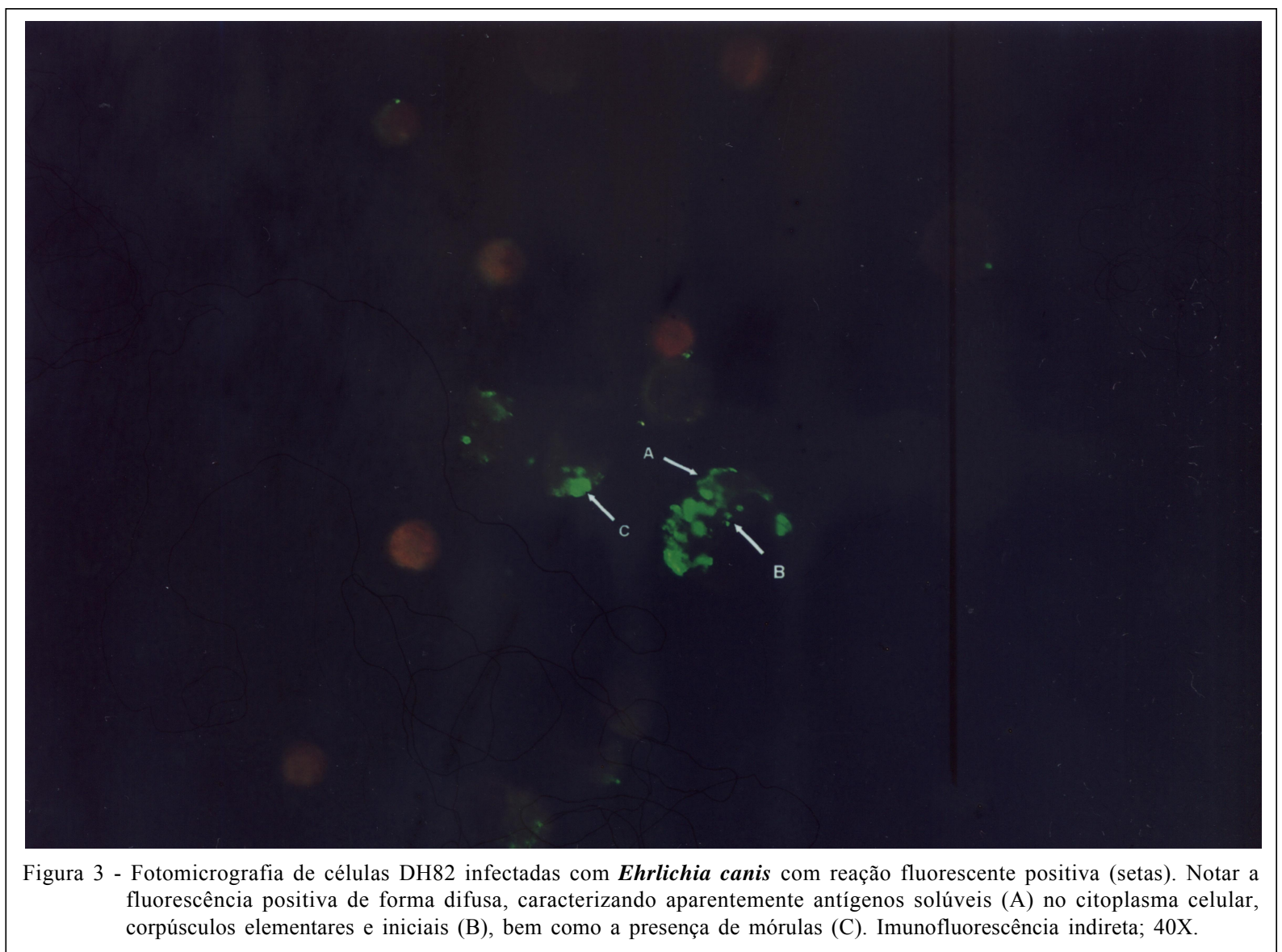

\section{AGRADECIMENTOS}

À Fundação de Amparo a Pesquisa do Estado de São Paulo (FAPESP), processo 04/01638-0, pela bolsa de doutorado de D.M. Aguiar e pelos recursos destinados a este estudo. Ao Médico Veterinário Msc Richard Campos Pacheco, pelo auxílio no desenvolvimento deste trabalho.

\section{COMISSÃO DE BIOÉTICA}

O presente trabalho está de acordo com os princípios éticos de experimentação animal e biossegurança da Comissão de Bioética da faculdade de Medicina Veterinária e Zootecnia da Universidade de São Paulo, sendo aprovado sob o protocolo $623 / 2005$.

\section{REFERÊNCIAS}

COSTA, J.O. et al. Ehrlichia canis infection in dogs in Belo Horizonte - Brazil. Arq Esc Vet Univ Minas Gerais, v.25, p.199-200, 1973.

DAWSON, J.E. et al. Serological diagnosis of human ehrlichiosis using two Ehrlichia canis isolates. J Infect Dis, v.163, p.564$567,1991$.

DAWSON, J.E. et al. Human endothelial cells as an alternative to DH82 cells for isolation of Ehrlichia chaffeensis, E. canis, and Rickettsia rickettsii. Pathobiol, v.61, p.293-296, 1993.
DUMLER, J.S. et al. Reorganization of genera in the families Rickettsiaceae and Anaplasmataceae in the order Rickettsiales: unification of some species of Ehrlichia with Anaplasma, Cowdria with Ehrlichia and Ehrlichia with Neorickettsia, descriptions of six new species combinations and designation of Ehrlichia equi and HGE agent as subjective synonyms of Ehrlichia phagocytophila. Int J Syst Evol Microbiol, v.51, p.2145-2165, 2001

HASEGAWA, M.Y. et al. Evaluation of neutrophil oxidative metabolism in canine monocytic ehrlichiosis. Vet Clin Pathol, v.34, p. 213-217, 2005.

HELMET, I.E. et al. Serial propagation of Ehrlichia canis in primary canine peripheral blood monocytes cultures. Cornell Vet, v.70, p.37-42, 1980.

KEYSARY, A. et al. The first isolation, in vitro propagation, and genetic characterization of Ehrlichia canis in Israel. Vet Parasitol, v.62, p.331-340, 1996.

KEYSARY, A. et al. Cultivation of Ehrlichia canis in a continuous BALB/C mouse macrophage cell culture line. J Vet Diagn Invest, v.13, p.521-523, 2001.

KUYLER-DOYLE, C. et al. Detection of medically important Ehrlichia by quantitative multicolor taqman real-time PCR of the $d s b$ gene. J Mol Diagn, v.7, n.4, p.504-510, 2005.

Ciência Rural, v.37, n.3, mai-jun, 2007. 
LABARTHE, N. et al. Serologic prevalence of Dirofilaria immintis, Ehrlichia canis and Borrelia burgdorferi infection in Brazil. Vet Ther, v.4, p.67-75, 2003.

LABRUNA, M.B.; PEREIRA, M.C. Carrapatos em cães no Brasil. Clin Vet n.30, p.24-32, 2001.

MACHADO, R.Z. Ehrlichiose canina. Rev Bras Parasitol Vet, v.13, supl.1, p.53-57, 2004.

MCBRIDE, J.W. et al. Immunodiagnosis of Ehrlichia canis infection with recombinant proteins. J Clin Microbiol, v.39, n.1, p.315-322, 2001

MOREIRA, S.M. et al. Retrospective study (1998-2001) on canine ehrlichiosis in Belo Horizonte, MG, Brazil. Arq Bras Med Vet Zoot, v.55, p.141-147, 2003.

PADDOCK, C.D. et al. Isolation and characterization of Ehrlichia chaffeensis strain from patients with fatal ehrlichiosis. J Clin Microbiol, v.35, p.2496-2502, 1997.

PEREZ, P. et al. Ehrlichia canis detection in symptomatic humans in Venezuela. In: INTERNATIONAL CONFERENCE
ON RICKETTSIAE AND RICKETTSIAL DISEASES, 4., 2005, Logroño, Espanha. Anais... Logroño: American Society for Rickettsiae and Rickettsiology, 2005. p.45.

RISTIC, M. et al. Serological diagnosis of tropical canine pancytopenia by indirect immunofluorescence. Infect Immun, v.6, p.226-231, 1972.

STEPHENSON, E.H.; OSTERMAN, J.V. Canine peritoneal macrophages: cultivation and infection with Ehrlichia canis. Am J Vet Res, v.38, n.11, p.1815-1819, 1977.

TORRES, H.M. et al. Isolamento e propagação da Ehrlichia canis em células DH82 e obtenção de antígeno para a reação de imunofluorescência indireta. Rev Bras Cien Vet v.9, n.2, p.77-82, 2002.

UNVER A. et al. Molecular and antigenic comparison of Ehrlichia canis isolates from dogs, ticks, and a human in Venezuela. J Clin Microbiol, v.39, p.2788-2793, 2001.

WELLMAN, M.L. et al. A macrophage-monocyte cell line from a dog with malignant histiocytosis. In Vitro Cell Dev Biol, v.24, p.223-229, 1988. 